\title{
Silver-coated nylon dressings for pediatric burn victims
}

\author{
Daniel E Borsuk MD CM MBA ${ }^{1}$, Michel Gallant MD ${ }^{1,2}$, Diane Richard RN BSc ${ }^{3,4}$, \\ H Bruce Williams MD FRCSC FACS ${ }^{1,2,4}$
}

\begin{abstract}
DE Borsuk, M Gallant, D Richard, HB Williams. Silver-coated nylon dressings for pediatric burn victims. Can J Plast Surg 2007;15(1):29-31.
\end{abstract}

BACKGROUND: Silver dressings are a proven method for burn treatment. Current challenges associated with burn treatment include pain management and limited hospital resources. A new silver-coated nylon dressing was used at the Montreal Children's Hospital (Montreal, Quebec) to help reduce traumatic dressing changes and cost.

METHODS: Burn victims in a pediatric patient population were followed over two years. Patients were excluded if they were evaluated more than $48 \mathrm{~h}$ postburn or if the burn affected less than $5 \%$ of the total body surface area. The same burn team admitted and treated all case subjects, and one dressing nurse recorded and monitored all progress throughout the study to ensure standardization.

RESULTS: Fifteen patients were included in the study. The average number of dressing changes needed was 4.13 , with a median of three changes. The average total body surface area burned was $8 \%$, with a mean of 13.9 days before superficial wounds were re-epithelialized. The average length of in-hospital stay was four days. The cost was \$388 less for silver-coated nylon dressings than for silver sulfadiazine cream for seven days of treatment. Silver-coated nylon dressings did not leave any residue or pseudoeschar on the wounds and were easily maintained at home.

CONCLUSION: The silver-coated nylon dressings are as effective as other silver dressings used for pediatric burn victims. The dressings are less traumatic, require fewer resources and do not leave wound residue compared with other dressings.

Key Words: Burn; Plastic surgery; Prospective study; Silver; SilverLeaf; Sulfadiazine; treatment

Silver has been used for its antimicrobial properties for thou$\checkmark$ sands of years. Herodotus, the Greek philosopher and historian, described the use of silver for water purification before the time of Christ. The famous Roman physician, Pliny the Elder, wrote in his encyclopedia Natural History in 79 AD that silver "has healing properties in plasters, being extremely effective in causing wounds to close" (1). More recently, silver leaf was used to treat infected wounds of troops during the First World War. Then, in 1968, Fox (2) first described the use of silver sulfadiazine for burn treatment, which has since become a standard antimicrobial for burn care. Despite the great success of silver treatment for burns, certain limitations still exist.

\section{Pansements de nylon imprégnés d'argent chez les enfants ayant subi des brûlures}

CONTEXTE : Les pansements à l'argent sont une méthode éprouvée dans le traitement des brûlures. Les problèmes actuels liés au traitement des brûlures sont la douleur et les ressources hospitalières limitées. Un nouveau passement de nylon imprégné d'argent a été utilisé à l'Hôpital de Montréal pour enfants afin d'atténuer le traumatisme lié aux changements de pansements et de réduire les coûts.

MÉTHODE : Une population d'enfants ayant subi des brûlures a été suivie pendant deux ans. Les enfants qui ont été évalués $48 \mathrm{~h}$ après l'événement ou ceux dont les brûlures couvraient moins de $5 \%$ de la surface corporelle totale ont été exclus de l'étude. La même équipe a suivi tous les sujets pendant leur séjour à l'hôpital, et une infirmière affectée aux changements de pansements a consigné et surveillé l'évolution des patients tout au long de l'étude afin d'assurer l'uniformité.

RÉSULTATS : Quinze enfants ont été admis dans l'étude. Le nombre moyen de changements de pansements était de 4,13; et le nombre médian, de trois. La surface corporelle totale brûlée était de $8 \%$ en moyenne, et le nombre moyen de jours avant la réépithélisation des lésions superficielles était de 13,9. La durée moyenne du séjour à l'hôpital s'élevait à 4 jours. Le coût des pansements de nylon imprégnés d'argent était de 388 \$ inférieur à celui du traitement par l'application de crème de sulfadiazine d'argent pendant sept jours. Les pansements de nylon imprégnés d'argent n'ont pas laissé de dépôt sur les blessures ou provoqué de pseudo-escarres et ils se sont montrés faciles d'entretien à domicile.

CONCLUSION : Les pansements de nylon imprégnés d'argent sont aussi efficaces que les autres pansements à l'argent chez les enfants ayant subi des brûlures. Les nouveaux pansements causent moins de traumatisme et nécessitent moins de ressources que les autres types de pansement et ils ne laissent aucun dépôt sur les lésions.

\footnotetext{
${ }^{1}$ Faculty of Medicine, McGill University; ${ }^{2}$ Division of Plastic $\mathcal{E}$ Reconstructive Surgery; ${ }^{3}$ Pediatric and Adolescent Trauma Program; ${ }^{4}$ Montreal Children's Hospital, McGill University Health Centre, Montreal, Quebec
}

Correspondence and reprints: Dr Daniel E Borsuk, 2128 Fulton Road, Montreal, Quebec H3R 2L4. Telephone 514-296-6899,

fax 514-738-7796, e-mail dborsuk@gmail.com 

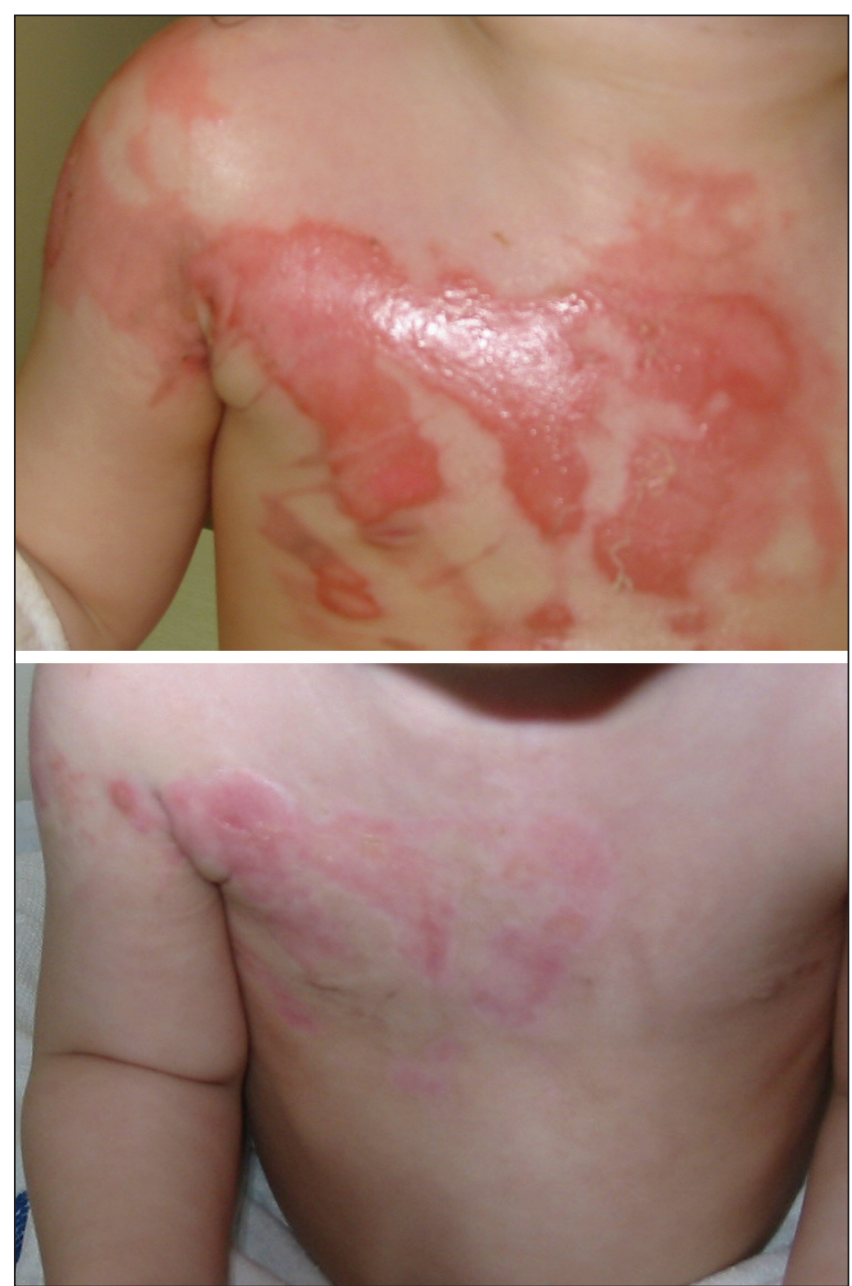

Figure 1) Top A 15-month-old girl with superficial second-degree burns from boiling water on the day of injury. Bottom Wound healed 11 days postburn after treatment with silver nylon dressings

successful prevention of radiation dermatitis in patients undergoing chemotherapy and external beam radiotherapy.

\section{METHODS}

A two-year prospective study was performed at the Montreal Children's Hospital, Montreal, Quebec. Patients were excluded if they were admitted to hospital more than $48 \mathrm{~h}$ postburn or suffered a burn less than $5 \%$ of total body surface area (TBSA). To standardize the treatment, all patients were triaged and followed by an assigned nurse and burn team. One plastic surgeon was responsible for assessing the depth and degree of all burns. Dressing changes were performed under the guidance of the burn team plastic surgeon and nurse. An anesthetist was available to administer all sedatives and analgesics for each procedure if necessary.

The silver-coated nylon dressings can be applied and maintained for up to one week when sterile water is used to moisten the dressing every $8 \mathrm{~h}$. Sterile water is used instead of normal saline because the chloride ions in normal saline react with silver to form silver chloride crystals, which reduce the release of ionic silver. Maximum release of ionic silver occurs in water devoid of anions, which react with the silver cation. Two catheters were placed on top of the dressings to allow for easy administration of water at home.
TABLE 1

Results of a study examining burn victims in a pediatric patient population

\begin{tabular}{lcc}
\hline & Average & Median \\
\hline Patients, $\mathrm{n}$ & 15 & \\
Male:Female & $7: 8$ & 3 \\
Age, years & 5.5 & 3 \\
Dressing changes, $\mathrm{n}$ & 4.13 & \\
Total body surface area affected, \% & 8 & \\
Source of burn, $\mathrm{n}$ & & \\
$\quad$ Fire & 2 & \\
$\quad$ Water (scald) & 12 & \\
$\quad$ Stove element & 1 & \\
Superficial partial thickness, $\mathrm{n}$ & 11 & \\
$\quad$ Days before healed & 13.9 & \\
Deep partial thickness, $\mathrm{n}$ & 4 & \\
$\quad$ Days before healed & 28.5 & \\
Grafted, $\mathrm{n}$ & 4 & \\
Days in hospital, $\mathrm{n}$ & 4 & \\
Complications, $\mathrm{n}$ & 1 (infection) \\
\hline
\end{tabular}

The dressings were changed under adequate analgesia, including general anaesthesia, intravenous sedation or oral medications. Dressings were changed in accordance with standardized guidelines. Dressings were discontinued when wounds were re-epithelialized and dry.

The wound nurse was responsible for all data recordings. Length of wound healing, length of hospital stay and the number of dressing sheets used were all documented. Cost of dressing changes was calculated based on the study average of a burn size $8 \%$ of TBSA and on dressing a wound for seven days on a $55 \mathrm{~kg}$, 12-year-old boy with a $0.124 \mathrm{~m}^{2}$ burn. Photographs were taken at every dressing change with consent of the patients' guardians. As well, wound residue, drainage and any complications were recorded for study.

\section{RESULTS}

In the present two-year prospective study, 15 burn victims met the selection criteria, with a male to female patient ratio of 7:8 and an average age of 5.5 years. Scalding was the most common cause of burns in the study population (12 of 15 burns), followed by fire $(n=2)$ and stove element $(n=1)$. The average number of dressing changes needed was 4.13 , with a median of three changes. All burns were partial thickness: 11 were superficial and four were deep. The average TBSA burned was $8 \%$, taking a mean of 13.9 days before the superficial burns were healed and 28.5 days before the deep burns were completely re-epithelialized after grafting (Figure 1). The average length of in-hospital stay was four days, with a median of two days (Table 1).

The approximated cost for dressing a wound for seven days in a $55 \mathrm{~kg}, 12$-year-old boy with an $8 \%$ TBSA burn equalling $0.124 \mathrm{~m}^{2}$ was less when the silver-coated nylon dressing was applied compared with Flamazine (Smith \& Nephew Inc, Canada), a silver sulfadiazine cream. The total cost of the silvercoated nylon dressing was $\$ 308$ compared with $\$ 696$ for the Flamazine dressings. The increased cost of the Flamazine dressings is most attributed to the increased cost of staffing the daily dressing changes; $\$ 350$ versus $\$ 50$ for the silver-coated nylon 
TABLE 2

Cost of weekly dressing changes for a $0.124 \mathrm{~m}^{2}$ burn

\begin{tabular}{lcc}
\hline & Flamazine* $^{*}$ & SilverLeaf $^{\dagger}$ \\
\hline Dressings & $\$ 346.22$ & $\$ 258.46$ \\
Nursing & $\$ 350.00$ & $\$ 50.00$ \\
Total & $\$ 696.22$ & $\$ 308.46$ \\
\hline
\end{tabular}

${ }^{*}$ Smith \& Nephew Inc, Canada; ${ }^{\dagger} D R$ Medical Inc, Canada

dressing (Table 2). The nursing cost was based on a two-nurse team for a $1 \mathrm{~h}$ dressing change. The cost of sedation and doctor's fee was not included.

The nurses and burn surgeon documented no burn residue or pseudoeschars on any of the wounds during the dressing changes. The only complication documented was one hand infection that was successfully treated with five days of oral antibiotics.

\section{DISCUSSION}

The results of the trial demonstrated that the silver-coated nylon dressings were effective in treating the burn patients, with minimal dressing changes. Although no pain scales were employed during the study, reducing the number of dressing changes significantly reduced the trauma for the young patients. The dressings are able to stay on the wound up to seven days when kept moist with sterile water. The dressings come in different shapes, such as gloves and boots, and can be tailormade to fit particular wound dimensions (Figure 2).

The silver-coated nylon dressings were less costly to the burn division than previously used silver sulfadiazine dressings. The cost difference between the two dressings clearly demonstrates that the silver-coated nylon dressings may save the hospital already scarce capital and human resources.

An additional advantage of the silver-coated nylon dressings is that the dressings release ionic silver, not metallic silver or silver salts that are known to stain the dermis. The absence of dressing residue and pseudoeschar, which may be seen following the application of silver sulfadiazine and other silverbased dressings, allows for more accurate burn depth estimation and treatment by attending surgeons (Figure 3).

The results indicated that superficial burns were healed in fewer than 14 days. The burn wounds may have been healed before the final dressing change, however, due to the extended period between changes, the actual time interval from accident to healing could not be accurately measured.

Some limitations of the study were the small sample size and limited burn size and depth. This study was designed to observe and document the results of silver-coated nylon dressings and did not compare the product with other, similar, dressings, such as Acticoat (Smith \& Nephew, Canada) (4).

\section{CONCLUSIONS}

SilverLeaf is a new silver impregnated nylon dressing that is effective at treating pediatric burn victims with burns of less than 15\% TBSA. Our study clearly proves that satisfactory results for pediatric burn victims can be attained with silver nylon dressings. The dressings are changed less frequently than

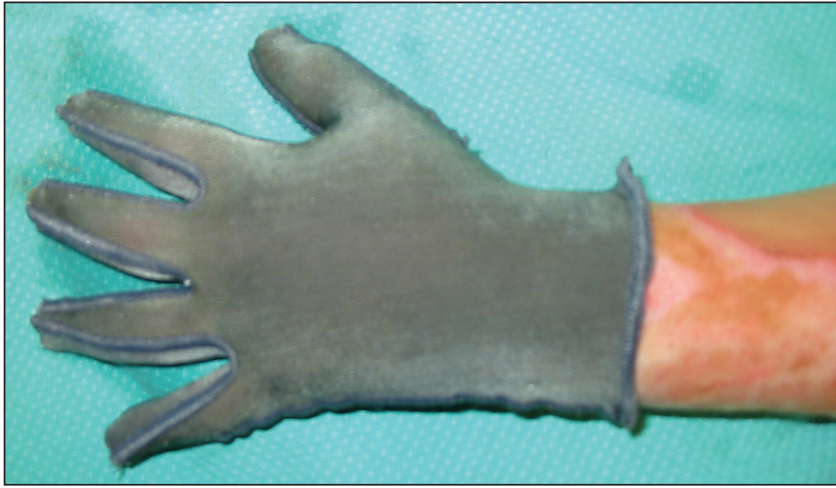

Figure 2) A five-year-old girl three days postburn with flame, wearing a silver-coated nylon glove

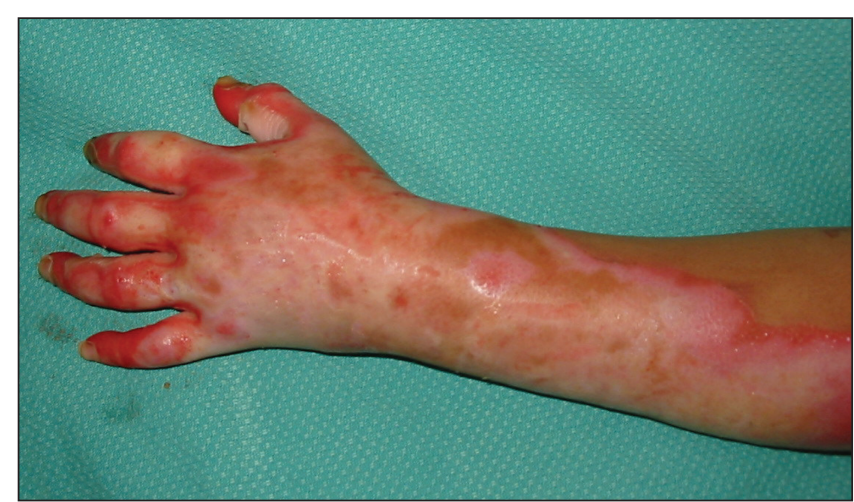

Figure 3) Same patient as in Figure 2 after removal of silver-coated nylon dressing. Note the absence of wound residue and pseudoeschar

conventional dressings with silver sulfadiazine, and therefore reduce the trauma experienced by the patients and reduce the costs to the burn unit. Moreover, SilverLeaf dressings come in many shapes and sizes, such as gloves and boots, and can be tailor-made to fit the particular burn wound, making them easy to apply and maintain at home. Finally, the dressings do not leave a residue or pseudoeschar on wounds, making wound estimation easier and more reliable in pediatric burn victims. Silverleaf is a cost-effective, easy-to-use burn dressing that is a good alternative to other dressings currently available on the market.

\section{REFERENCES}

1. Pliny the Elder. Book XXXIII, Part XXXV, Vol IX. In: Natural History. Rome, 79 A.D.

2. Fox CL Jr. Silver sulfadiazine - a new topical therapy for Pseudomonas in burns. Therapy of Pseudomonas infection in burns. Arch Surg 1968;96:184-8.

3. Vuong T, Franco E, Lehnert S, et al. Silver leaf nylon dressing to prevent radiation dermatitis in patients undergoing chemotherapy and external beam radiotherapy to the perineum. Int J Radiat Oncol Biol Phys 2004;59:809-14.

4. Dunn K, Edwards-Jones V. The role of Acticoat with nanocrystalline silver in the management of burns. Burns 2004;30(Suppl 1):S1-9. 